lining the under side of the cover with a thick sheet of asbestos. The outside of the cover is plated with nickel which diminishes radiation outward. Repeated trials with a standard thermometer inserted in the oven at $t$, and between the walls at $\mathbf{S}$, have shown a difference of only two-tenths of a degree between the boiling water and the drying compartment. Trials with several ordinary chemical thermometers have shown a variation from $99^{\circ} \mathrm{C}$. to $10 \mathrm{r}^{\circ} \mathrm{C}$. in the oven.

The oven was made for the Experiment Station by Richards \& Co., of New York.

NEW HAMPSHIRE EXPERIMENT STATION,

IURHAM, N. H.

\title{
AN IMPROVED GOOCH CRUCIBLE.
}

BY W. A. PUCKNER.

Received Norember 14,1893 .

SOMETIME ago I adopted a slight improvement in the use $S$ of the Gooch crucibles with which I am so well pleased that I wish to call attention to it.

It is an occasional, if not frequent, occurrence, that while pouring a precipitate on the asbestos, this becomes loose, and floats in the liquid, thus allowing the precipitate to pass through the perforations.

Another objection, which is sometimes urged against this method of filtration, is that the asbestos becomes mixed with the precipitate making an examination regarding purity diffcult.

$\mathrm{My}$ modification consists in placing a perforated platinum plate, such as are used in the Gooch crucibles made of porcelain, and which may be obtained separately, on the layer of asbestos. This layer need be but very thin as there is now not the least danger of disarranging it while pouring on the liquid. After drying or ignition the precipitate can be obtained perfectly clean and with the loss of but a few milligrams.

HFIDELBERG UNIVERSITY. 